\title{
Changes in brain and behavior during food-based decision-making following treatment of anorexia nervosa
}

Karin Foerde ${ }^{1,2}$, B. Timothy Walsh ${ }^{1,2}$, Maya Dalack', Nathaniel Daw ${ }^{3}$, Daphna Shohamy ${ }^{4}$ and Joanna E. Steinglass ${ }^{1,2^{*}}$

\begin{abstract}
Background: Anorexia nervosa is a severe illness with a high mortality rate, driven in large part by severe and persistent restriction of food intake. A critical challenge is to identify brain mechanisms associated with maladaptive eating behavior and whether they change with treatment. This study tested whether food choice-related caudate activation in anorexia nervosa changes with treatment.

Methods: Healthy women $(n=29)$ and women hospitalized with anorexia nervosa $(n=24)$, ages 18 to 40 years, completed a Food Choice Task during fMRI scanning at two timepoints. Among patients, procedures occurred upon hospital admission (Time 1) and again after patients had gained to normal weight (Time 2). Healthy controls were tested twice at an interval group-matched to patients. Choice-related caudate activation was assessed at each timepoint, using parametric analyses in an a priori region of interest.

Results: Among patients, the proportion of high-fat foods selected did not change over time $\left(p^{\prime} s>0.47\right)$, but decreased neural activity in the caudate after treatment was associated with increased selection of high-fat foods $\left(r_{23}=-0.43, p=0.037\right)$. Choice-related caudate activation differed among women with anorexia nervosa vs healthy control women at Time 1 (healthy control: $M=0.15 \pm 0.87$, anorexia nervosa: $M=0.70 \pm 1.1, t_{51}=-2.05, p=0.045$ ), but not at Time 2 (healthy control: $M=0.18 \pm 1.0$, anorexia nervosa: $\left.M=0.37 \pm 0.99, t_{51}=-0.694, p=0.49\right)$.

* Correspondence: js1124@cumc.columbia.edu

'New York State Psychiatric Institute, 1051 Riverside Drive, Unit 98, New York, NY 10032, USA

${ }^{2}$ Psychiatry Department, Columbia University Irving Medical Center, 1051 Riverside Drive, Unit 98, New York, NY 10032, USA

Full list of author information is available at the end of the article

(c) The Author(s). 2021 Open Access This article is licensed under a Creative Commons Attribution 4.0 International License, which permits use, sharing, adaptation, distribution and reproduction in any medium or format, as long as you give appropriate credit to the original author(s) and the source, provide a link to the Creative Commons licence, and indicate if changes were made. The images or other third party material in this article are included in the article's Creative Commons licence, unless indicated otherwise in a credit line to the material. If material is not included in the article's Creative Commons licence and your intended use is not permitted by statutory regulation or exceeds the permitted use, you will need to obtain permission directly from the copyright holder. To view a copy of this licence, visit http://creativecommons.org/licenses/by/4.0/. The Creative Commons Public Domain Dedication waiver (http://creativecommons.org/publicdomain/zero/1.0/) applies to the data made available in this article, unless otherwise stated in a credit line to the data. 


\begin{abstract}
(Continued from previous page)
Conclusions: Caudate activity was more strongly associated with decisions about food among individuals with anorexia nervosa relative to healthy comparison individuals prior to treatment, and decreases in caudate engagement among individuals with anorexia nervosa undergoing treatment were associated with increases in high-fat food choices. The findings underscore the need for treatment development that more successfully alters both eating behavior and the neural mechanisms that guide it.
\end{abstract}

Keywords: Anorexia nervosa, Treatment, fMRI, Neuroscience, Longitudinal, Eating behavior

\section{Plain English summary}

Treatment that leads to full weight restoration in anorexia nervosa (AN) is accompanied by improvements in psychological symptoms. Yet, restrictive eating does not improve. Prior studies have shown that different neural circuits are engaged when deciding what to eat for patients with AN, compared with healthy controls. Here, we tested whether there were changes in brain activation associated with eating after weight restoration. Overall, food choices did not change with weight restoration, again showing that restrictive eating is resistant to change. However, changes among patients with AN showed a significant association between increased selection of high-fat foods and decreased activity in the caudate, with treatment. These findings highlight the importance of specific brain systems related to eating in the treatment of AN.

\section{Background}

The first step in the treatment of anorexia nervosa (AN) is weight restoration [1]. Behaviorally-based structured programs incentivizing patients with $\mathrm{AN}$ to consume adequate calories and normative macronutrient composition (i.e., at least $30 \% \mathrm{kcal}$ from dietary fat) have high success rates [2]. Yet, relapse and rehospitalization of adults with AN are common, even after full weight restoration [3]. A central behavioral disturbance that contributes to relapse and chronicity of illness is the persistent restriction of food intake [4]. The neural mechanisms that underlie decisions about eating in AN have become a focus of recent research, providing an opportunity to test empirically how such mechanisms are affected by treatment. Increased understanding of the effects of treatment on neural mechanisms underlying the decision of what to eat may be useful in identifying biomarkers and new treatment targets.

In standard treatment programs for AN, renourishment is accomplished by providing appropriate nutrition, supervision around meals, and behavioral and psychological therapy to promote healthy eating and weight restoration [2]. Success rates for inpatient treatment are high in terms of weight normalization, resolution of medical instability, and improvement in associated psychological symptoms including depression and anxiety [5]. In these structured settings, individuals with AN are able to consume the $\sim 4000 \mathrm{kcal}$ per day that are required to gain weight at an appropriate pace. And yet, as soon as treatment incentives are removed after hospital discharge, these same individuals struggle to consume adequate nutrition and often lose weight $[6$, 7]. In two laboratory meal studies, hospitalized patients with AN showed significant improvement in psychological measures after successful weight restoration, but still consumed significantly fewer calories and less fat than healthy volunteers at both timepoints $[8,9]$. The persistence of this maladaptive eating pattern indicates that it is important to understand this behavior.

Decision science has recently yielded advances in understanding the behavioral, computational, and neural mechanisms of choices [10-13]. Much of this research has involved food choices, partly for convenience of experimental design, leading to insights of particular relevance for eating disorders. Choice is a complex phenomenon that incorporates multiple cognitive and neural processes, such as attention, valuation, and action selection [14]. In decisions about what to eat, healthiness and tastiness have repeatedly been shown to be distinguishable values that are integrated into choice selection [12, 15-17]. The neurobiology of food choice has been shown to involve regions associated with value representations ventromedial prefrontal cortex (VMPFC) and self-control dorsolateral prefrontal cortex (DLPFC) [12]. The neural mechanisms of decision-making, and decisions about what foods to eat, have received relatively little attention in AN. Yet understanding the neural bases of maladaptive eating behavior may be important in order to improve treatment.

In two studies from our group, food choices made by adult women with AN were associated with neural activity in the dorsal striatum (specifically, the anterior caudate) $[18,19]$, which differed from healthy peers. This research used a food choice task that has been demonstrated to capture the maladaptive restrictive choices of patients with AN $[20,21]$ with both the restricting and the binge-eating/purging subtypes [22]. Task-based choices have been related to actual food intake in a laboratory meal [19], and test-retest reliability of the task has been demonstrated among healthy individuals [23]. 
However, changes in the neural underpinnings of decision-making about food have not been examined after weight restoration treatment.

Here, we examined whether food choice-related activation in regions of interest identified in previous studies $[12,19,24]$, primarily the anterior caudate, VMPFC, and DLPFC changed, with treatment. Patients with AN participated in a Food Choice Task during fMRI scanning twice, once at admission for inpatient weight restoration treatment, and again after treatment. Change with treatment was compared with a group of healthy comparison (HC) women, who were studied twice, at an interval matched to the AN group. We hypothesized that individuals with AN would show greater choice-related activation of the anterior caudate as compared with $\mathrm{HC}$ and that this difference between groups would diminish after patients received weight restoration treatment, whereas groups would not differ in choice-related activation in the VMPFC and DLPFC. We additionally explored differences between groups and changes with treatment in choice-related, as well as tastiness and healthiness rating-related, activation in whole-brain analyses.

\section{Methods}

\section{Participants}

Participants were female $\mathrm{HC}$ and female inpatients with $\mathrm{AN}$ at the New York State Psychiatric Institute (NYSPI). Eligible patients met DSM-5 [25] criteria for AN at the time of admission assessed via Eating Disorders Assessment for DSM-5 [26]. HC were included if they had no current or lifetime psychiatric illness (including an eating disorder) and had a body mass index (BMI) between 18.5 and $25.0 \mathrm{~kg} / \mathrm{m}^{2}$. In both groups, individuals were excluded if they were taking psychotropic medication, had a known history of a neurological disorder or injury, had any contraindication to MRI, or were pregnant. All participants were right-handed, between the ages 18-40 years, and had an estimated IQ $>80$. Participants were enrolled between November 2015 and August 2018.

Procedures occurred twice, once upon admission (Time 1) and once again after weight restoration (Time 2) for individuals with $\mathrm{AN}$, and within 1-2 months for $\mathrm{HC}$, to match the treatment time frame. Inpatient treatment at NYSPI is provided at no cost and consists of a behaviorally-based program aimed at full weight restoration [2] with a BMI goal between $19.5-20.5 \mathrm{~kg} / \mathrm{m}^{2}$. HC were compensated $\$ 150$ for participation at each timepoint (\$300 for both).

Only data from individuals who completed the Choice phase of the Food Choice Task during neuroimaging at both timepoints were analyzed. Time 1 data from these participants were included in one previous publication of food choice, focused on individuals across a spectrum of restrictive eating [18]. Of $31 \mathrm{HC}$, two were excluded from analyses due to loss of neuroimaging data (1 scanner error, 1 excessive motion) leading to a study sample of $29 \mathrm{HC}$. Of $26 \mathrm{AN}$, two were excluded due to a loss of task responses during neuroimaging, leaving a study sample of 24 AN (9 restricting subtype and 15 bingeeating/purging subtype). Two HC were additionally excluded from the Healthiness rating phase (1 due to excessive motion, 1 due to image artifact), and one AN was additionally excluded from the Healthiness and Tastiness rating phase due to excessive motion.

This study was approved by the NYSPI Institutional Review Board and all participants provided written informed consent.

\section{Procedure}

Height was measured on a Seca 240 wall-mounted stadiometer. Weight was measured in the morning at each timepoint on a Detecto balance-beam scale.
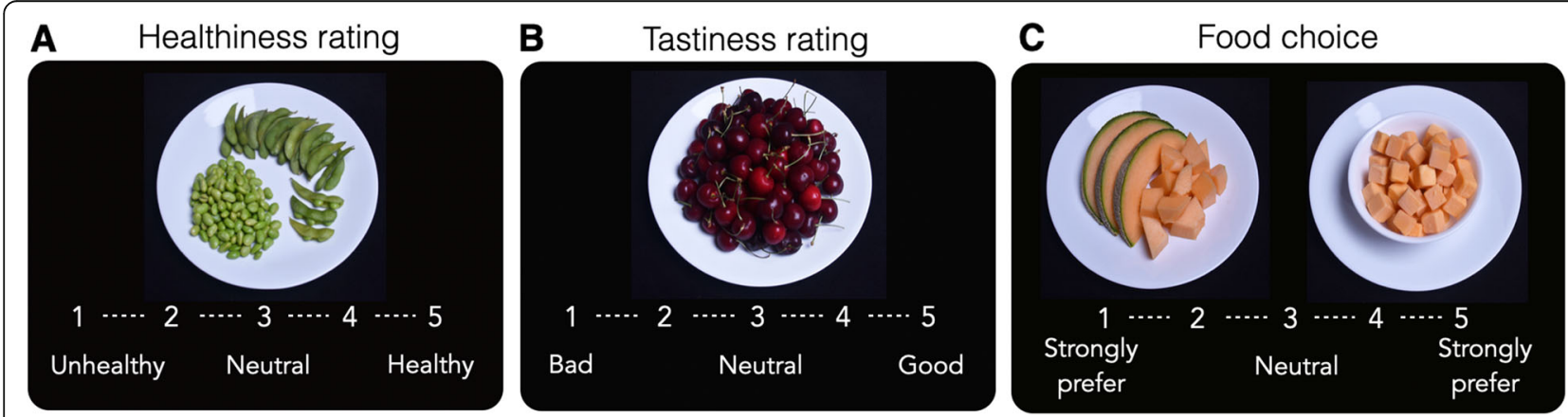

Fig. 1 Food Choice Task. The task consisted of two rating phases and a choice phase. In each phase participants made decisions about 76 food items. On each trial, the food stimulus was presented for $4 \mathrm{~s}$, during which the participant made her response. a Healthiness rating phase. Participants rated the healthiness of each food item on five-point Likert scale from Bad to Good (or Good to Bad, counterbalanced across participants). $\mathbf{b}$ Tastiness rating phase. Participants rated the tastiness of each food item on five-point Likert scale from Unhealthy to Healthy (or Healthy to Unhealthy, counterbalanced across participants). c Choice phase. On each trial, participants indicated their preference for a changing food item (shown on the right) relative to a repeated reference item (previously rated neutral on healthiness and tastiness; shown on the left). After task completion, one Choice trial was randomly selected and the participant served a snack-sized portion of the food selected on that trial 
Participants were given a standardized lunch $(4 \mathrm{oz}$. turkey breast, 2 slices whole wheat bread, 1 packet mayonnaise, Nutrigrain bar, and $8 \mathrm{oz}$. water, $\sim 500 \mathrm{kcal})$ at noon. At Time 2, for patients with AN, the posttreatment standardized lunch was increased in calories, such that the percent of the daily caloric prescription was the same at both timepoints. At approximately 2 $\mathrm{pm}$, participants were brought to the NYSPI MR Unit for the Food Choice Task with fMRI scanning. At the end of the task, the participant was served a snack based on one of her choices in the task (see below), observed by staff. Procedures at Time 2 were identical.

\section{Food choice task with fMRI (Fig. 1)}

Food Choice Task procedures have been described previously [19]. The task consisted of three phases: Healthiness rating, Tastiness rating, and a Choice block (Fig. 1). In each block, participants rated 76 foods on a 5-point scale. Half of the foods were classified as "high-fat" (> $30 \%$ of the calories from fat; images and macronutrient information available at Columbia Academic Commons: https://doi.org/10.7916/d8-497c-2724 [17]. The rating scale appeared at the bottom of the screen for each item and participants were instructed that they could rate it as "neutral" or along the scale. For the Healthiness block, the anchors were "Unhealthy" to "Healthy." For the Tastiness block, the anchors were "Bad" to "Good." For the Tastiness block, participants were additionally instructed to rate it only for tastiness. All task parameters (including order of the rating scale) were counterbalanced and randomized across participants. After completion of the rating scales, a "Reference" item was selected for each participant that had been rated by her as "Neutral" on both Healthiness and Tastiness. If no item neutral on both scales was identified, an item was selected that was rated neutral on Healthiness and 1 point in the positive direction on Tastiness, in order to minimize biasing choices based on taste value. In the Choice block, participants made a selection by indicating whether they 'Strongly Preferred' or 'Preferred' the Reference item (which was constant) or the other food (which varied on each trial) using a 5-point scale. To ensure that responses reflected true preferences, participants were told that they would be served one of their choices at the conclusion of the task. One Choice trial was randomly selected, and the participant received a snack-sized portion of the item chosen on that trial.

In all blocks, the food stimulus was presented for $4 \mathrm{~s}$ on each trial, during which the participant made her response. Each trial was followed by a fixation cross intertrial interval (ITI). The duration of ITIs was jittered for optimization of event-related fMRI design. Stimulus presentation sequence and timing were optimized using the optseq2 algorithm (http://surfer.nmr.mgh. harvard.edu/optseq/). Each learning run lasted $480 \mathrm{~s}$. Mean ITI $=2.3 \mathrm{~s}$, median $=2 \mathrm{~s}$, and range $=1-10 \mathrm{~s}$, across all three phases. All task phases were presented using Matlab and the Psychophysics toolbox [27].

Whole-brain imaging data were acquired on a GE $3 \mathrm{~T}$ MR750 scanner with a 32-channel phased-array head coil. Structural images were collected using a highresolution T1-weighted BRAVO pulse sequence $(1 \times 1 \times$ $1 \mathrm{~mm}$ voxel size) for image registration. Functional images were collected using a gradient echo $\mathrm{T} 2^{*}$-weighted echoplanar (EPI) sequence with blood oxygenation leveldependent $(\mathrm{BOLD})$ contrast $(\mathrm{TR}=2000 \mathrm{~ms}, \mathrm{TE}=19 \mathrm{~ms}$, flipangle $=77,3 \times 3 \times 3 \mathrm{~mm}$ voxel size, 45 contiguous axial slices, $\mathrm{FOV}=19.2$, interleaved acquisition). Each Food Choice Task run consisted of 240 volumes.

\section{Data analysis}

Demographic and clinical characteristics were compared using Student's t-tests and chi-square, as appropriate. Repeated measures ANOVA were used to test for significance of change over time within each group. Tests were two-tailed unless otherwise specified. Analyses were conducted in JASP [28] (https://jasp-stats.org), and alpha was set at $p=0.05$.

\section{Food choice task}

Rating and choice data were analyzed using multilevel regression models lme4 linear mixed effects package for $\mathrm{R}$ [29]. For the Choice phase, responses on the 5-point scale were converted to binary 'Yes' (1) or 'No' (0) preferences for the trial-unique food versus the Reference item, and neutral responses were omitted from analyses. Binomial choice data were modelled with multilevel logistic regression, in which participant choice (selection of the trial-unique food item over the reference food) was the dependent variable. Continuous outcome rating data from the Healthiness and Tastiness phases were modelled using multilevel linear regression. To assess relationships between ratings and choices, participant choice (selection of the trial-unique food item over the reference food) was the dependent variable and (zscored) healthiness and tastiness ratings entered as independent variables. The relationship between Healthiness and Tastiness was assessed with Healthiness ratings as the dependent variable and (z-scored) Tastiness ratings as the independent variable. In all analyses, Group $(\mathrm{HC} /$ AN, coded as -1/1), Food type (low-fat/high-fat, coded as $-1 / 1$ ), and Time (Time 1 /Time 2 , coded as $-1 / 1$ ) were entered as independent variables, and models included by-subject random intercepts and slopes and byitem (food images) random intercepts [30, 31].

Correlations between brain, behavior, and demographic measures were assessed using Pearson correlation. Robust regression was implemented as needed due to presence of 
outlier data points using the rlm function in the MASS package with bisquare weighting [32].

\section{fMRI analyses}

Imaging data were converted from DICOM to NIFTI format and preprocessed and analyzed using the FSL (http://fsl.fmrib.ox.ac.uk/fsl/) package version 6 (FMRIB's Software Library; Oxford Centre for Functional Resonance Imaging of the Brain, FMRIB) [33].

Image pre-processing Functional images were aligned using the MCFLIRT tool [34] and the six scan-to-scan head motion parameters estimated during motion correction obtained. The skull was removed from functional images using the brain extraction tool (BET) [35] and from structural images using Freesurfer [36, 37]. Spatial smoothing was applied with a Gaussian kernel of $5 \mathrm{~mm}$ (FWHM). Data and design matrix were high-pass filtered with a cutoff period of $100 \mathrm{~s}$. After analysis at the individual level, the results were normalized to a standard template: Functional images were first aligned to the T1-weighted image using a boundary-based registration method implemented in FSL6 (BBR) and then the structural image to the standard MNI152 2-mm template using FLIRT (12 degrees of freedom) and FNIRT (10$\mathrm{mm}$ warp resolution) [34, 38].

Analyses At the level of individual participants, each event was convolved with a canonical hemodynamic response function (except added confound regressors, see below) and entered into a general linear model (GLM). The temporal derivative of each regressor (except added confound regressors) was also included in the model. To account for any residual effects of subject movement, we included the six scan-to-scan head motion parameters estimated during motion correction as well as framewise displacement (FD) and root mean square intensity difference from one volume to the next (DVARS) [39] as confound regressors. In addition, volumes with FD and DVARS exceeding a threshold of 0.5 were modeled out by adding a single time point regressor for each volume to be 'dropped' from analysis [40]. Runs for which more than $25 \%$ of volumes were dropped were excluded from analysis: one Tastiness rating run at Time 1 (AN), two Healthiness rating runs at Time $2(1 \mathrm{HC}, 1 \mathrm{AN})$. The number of dropped volumes did not differ between groups (ps $>0.05$, Supplemental Table S1).

Parametric analysis of food choices and ratings were conducted (rating-related results in Supplemental Figure S1) [19]. Each person's choices were normalized to their own response range; analyses were therefore not biased by overall differences in choice preferences. The GLMs for the choice and rating phases included the following regressors: onsets for each trial on which a response was made (i), onsets for each trial on which a response was made parametrically modulated by the (demeaned) rating on that trial (ii) and the (demeaned) response time on that trial (iii), and onsets for missed trials (iv). Regressors i-iii were modeled with duration equal to the response time on each trial, and regressor iv with duration equal to the trial length $(4 \mathrm{~s})$. Motion and confound regressors were included as outlined above. Linear contrasts were performed on specific comparisons of interest. These contrasts were used for mixed-effects group analyses using FSL's FLAME 1 (FMRIB's local analysis of mixed effects) tool, using two-sample unpaired $t$-tests to compare groups and paired $t$-tests to compare changes between Time 1 and Time 2 .

\section{ROI analyses}

Based on a previous study indicating involvement of the right anterior caudate in food choices [19], an anatomical region of interest (ROI) was obtained from the HarvardOxford probabilistic atlas included in FSL, thresholded at $25 \%$ probability and anterior to $y=0$ (Fig. 3a). Additional ROIs were included based on their implication in food choices in healthy individuals, with the VMPFC involved in value-based decisions and the DLPFC implicated in self-control [12]. Moreover, VMPFC regions (e.g., OFC) have been implicated in studies of decision making in AN [41] and DLPFC has been used as a target for neuromodulation (rTMS) intervention in AN [20]. Six-mm spheres were created centered on MNI coordinates taken from a previous study using the Food Choice task [12]: VMPFC $(\mathrm{MNI}=$ [3 51 3]; Fig. 3b) and DLPFC (MNI = [- 4815 24]; Fig. 3c).

\section{Whole-brain analyses}

Whole-brain higher-level analyses were thresholded using clusters determined by $Z>3.1$ and a whole-brain corrected, FWE cluster significance threshold of $p=0.05$ [42]. For exploratory purposes, we additionally considered analyses thresholded at $Z>2.3$, FWE cluster significance threshold of $p=0.05$ [43].

Results are displayed on a study-specific mean anatomical image resulting from averaging all participants' normalized high-resolution structural images.

\section{Results}

Clinical characteristics of participants are presented in Table 1. Psychological measures differed between individuals with $\mathrm{AN}$ and $\mathrm{HC}$ at both timepoints, and the $\mathrm{AN}$ group showed improvement in all psychological measures and BMI from Time 1 to Time 2. At Time 2, AN and $\mathrm{HC}$ groups were well matched on BMI $\left(t_{51}=1.29\right.$, $p=0.20$ ). The average time between scans was similar in both groups $\left(\right.$ mean $_{\mathrm{HC}}: 49 \pm 21$ days; mean ${ }_{\mathrm{AN}}: 58 \pm 21$ days, $\mathrm{t}_{51}=-1.4, p=0.17$ ). 
Table 1 Demographics and clinical characteristics of participants

\begin{tabular}{|c|c|c|c|c|c|c|c|c|c|c|c|c|c|c|c|c|}
\hline & \multicolumn{6}{|c|}{ Time 1} & \multicolumn{6}{|c|}{ Time 2} & \multicolumn{4}{|c|}{ Time 1 versus Time 2} \\
\hline & \multicolumn{2}{|c|}{$\mathrm{HC}(n=29)$} & \multicolumn{2}{|c|}{ AN $(n=24)$} & \multirow[b]{2}{*}{$\mathbf{t}$} & \multirow[b]{2}{*}{$p$} & \multicolumn{2}{|c|}{$\mathrm{HC}$} & \multicolumn{2}{|l|}{ AN } & \multirow[b]{2}{*}{$\mathbf{t}$} & \multirow[b]{2}{*}{$p$} & \multicolumn{2}{|l|}{$\mathrm{HC}$} & \multicolumn{2}{|c|}{ AN } \\
\hline & $M$ & SD & $M$ & SD & & & $M$ & SD & $M$ & SD & & & $\mathrm{t}$ & $p$ & $t$ & $p$ \\
\hline Age (years) & 25.8 & 5.2 & 26.9 & 6.5 & -0.7 & 0.50 & & & & & & & & & & \\
\hline Caucasian $(n, \%)$ & 22 & $76 \%$ & 16 & $67 \%$ & $0.55^{\mathrm{a}}$ & 0.46 & & & & & & & & & & \\
\hline Estimated IQ & 117.3 & 13.4 & 112.0 & 9.5 & 1.7 & 0.11 & & & & & & & & & & \\
\hline LNS & 12.0 & 3.1 & 11.7 & 2.4 & 0.4 & 0.67 & & & & & & & & & & \\
\hline BMI (kg/m2) & 21.0 & 1.4 & 16.3 & 1.9 & 10.3 & $<.001$ & 21.0 & 1.6 & 20.5 & 0.9 & 1.4 & 0.17 & -0.33 & 0.75 & -13.4 & $<.001$ \\
\hline Duration of Illness (years) & & & 8.6 & 6.9 & & & & & & & & & & & & \\
\hline EDE-Q Global & 0.4 & 0.5 & 4.3 & 1.7 & -12.2 & $<.001$ & 0.4 & 0.4 & 2.8 & 1.3 & -9.1 & $<.001$ & -0.54 & 0.6 & 6.6 & $<.001$ \\
\hline TFEQ-Restraint & 5.9 & 4.2 & 17.4 & 3.6 & -10.6 & $<.001$ & 6.1 & 4.8 & 14.2 & 5.3 & -5.9 & $<.001$ & -0.43 & 0.67 & 3.9 & $<.001$ \\
\hline BDI & 2.1 & 2.3 & 31.1 & 13.4 & -11.5 & $<.001$ & 3.1 & 2.5 & 17.4 & 14.4 & -5.2 & $<.001$ & -1.94 & 0.06 & 5.3 & $<.001$ \\
\hline STAI(T) & 32.6 & 6.5 & 62.9 & 11.4 & -12.2 & $<.001$ & 32.9 & 8.2 & 56.0 & 12.2 & -8.2 & $<.001$ & -0.26 & 0.8 & 3.6 & 0.003 \\
\hline
\end{tabular}

${ }^{\mathrm{a} C h i}$ square statistic

Missing data: $\mathrm{BDI}$ is missing from 1 individual with $\mathrm{AN}$

$A N$ anorexia Nervosa, $B D I$ beck depression index [44], BMI body mass index, EDE- $Q$ eating disorder examination-questionnaire version [45], $H C$ healthy control, $L N S$ letter number sequence from the Weschler Adult Intelligence Scale [46], STAI(T) Spielberger trait anxiety inventory [47], TFEQ-Restraint Three Factor Eating Questionnaire Restraint subscale [48] Estimated IQ was assessed with the Wechsler Abbreviated Scale of Intelligence [49]

\section{Food choice task behavior}

All participants were able to respond within the response window, indicated by response rates exceeding $96 \%$ in all task phases and in both groups. Response rates did not differ between groups (ps $>0.25)$.

Choices of high-fat and low-fat foods (proportion of trials chosen over the Reference food) did not change significantly between Time 1 and Time 2 (ps $>0.16)$ (Fig. 2a). On average, the AN group chose high-fat foods less often than the $\mathrm{HC}$ group at both time points (Group $\mathrm{X}$ Food type interaction: Est $=-0.42, \mathrm{z}=-4.72, p<$ 0.00001; Supplemental Table S2; significant effect of Group for high-fat foods: Est $=-0.14, \mathrm{z}=-4.61, p<$ 0.0001 , but not for low-fat foods: Est $=-0.0008, \mathrm{z}=-$ $0.03, p=0.97)$.

Healthiness ratings did not change significantly with treatment (ps $>0.05$, Fig. 2b, Supplemental Table S3). High-fat foods were rated lower in healthiness than lowfat foods overall (Est: $-0.75, \mathrm{t}_{80.3}=-6.70, p=2.6 \times 10^{-9}$ ) and significantly more so among individuals with $\mathrm{AN}$ (Group X Food type interaction: Est $=-0.05, \mathrm{t}_{50.8}=-$ 2.02, $p=0.048$; significant effect of Group for high-fat foods: Est $=-0.15, \mathrm{t}_{51}=-2.84, p=0.006$, but not for low-fat foods: Est $=-0.04, \mathrm{t}_{51}=-1.15, p=0.26$ ).

Tastiness ratings did not change with treatment (Fig. 2c, Supplemental Table S4). Individuals with AN rated high-fat foods as less tasty than did HC (Food type $\mathrm{X}$ Group: Est $=-0.14, \mathrm{t}=-3.23, p=0.002$; Group: Est $=$ $-0.13, \mathrm{t}=-2.51, p=0.015$; significant effect of Group for high-fat foods: Est $=-0.28, \mathrm{t}_{51}=-3.22, \mathrm{p}=0.002$, but not for low-fat foods: Est $=0.007, \mathrm{t}_{51}=0.14, p=0.89$ ), and this pattern did not change over time (all other effects ps $>0.27$ ).

\section{Associations between ratings and choices}

Across both timepoints Healthiness influenced Choice more among individuals with AN relative to $\mathrm{HC}$ (Est = 0.49, $\mathrm{z}=3.94, p=8.2 \times 10^{-5}$ ) and Tastiness influenced Choice more among $\mathrm{HC}$ relative to individuals with $\mathrm{AN}$ (Est $=-0.46, \mathrm{z}=-3.69, p=0.0002$ ). There was a Time by Tastiness interaction (Est $=0.17, \mathrm{z}=2.08, p=0.037$ ), with Tastiness influencing Choice more at Time 2 in both groups (Fig. 2d, Supplemental Table S5). Healthiness was more strongly associated with Tastiness among $\mathrm{AN}$ relative to $\mathrm{HC}($ Est $=0.13, \mathrm{z}=2.19, \mathrm{p}=0.03$; Fig. $2 \mathrm{e}$, Supplemental Table S6) and the relationship between Healthiness and Tastiness ratings did not change over time (ps > 0.25).

\section{Neuroimaging \\ Anterior caudate}

During the Choice phase there was no significant interaction between Group and Time in a rmANOVA (F [1, $51]=1.19, p=0.28)$ nor a main effect of Time (F $[1,51]=$ $0.87, p=0.36)$. The main effect of Group approached statistical significance $(\mathrm{F}[1,51]=2.997, p=0.089)$ and groups differed significantly during Choice at Time 1 $\left(\mathrm{t}_{51}=-2.05, p=0.045\right)$. In contrast, group differences at Time 2 were not significant $\left(t_{51}=-0.694, p=0.49\right.$; Fig. 3a. During Healthiness and Tastiness ratings there were no effects of Group or Time (ps > 0.05; Supplemental Figure S1A).

We next examined whether change in caudate activation over time was related to changes in choice behavior in AN. Among individuals with AN, increased choice of high-fat foods was associated with decreased activation of the caudate during the Choice block $\left(r_{22}=-0.427\right.$, 

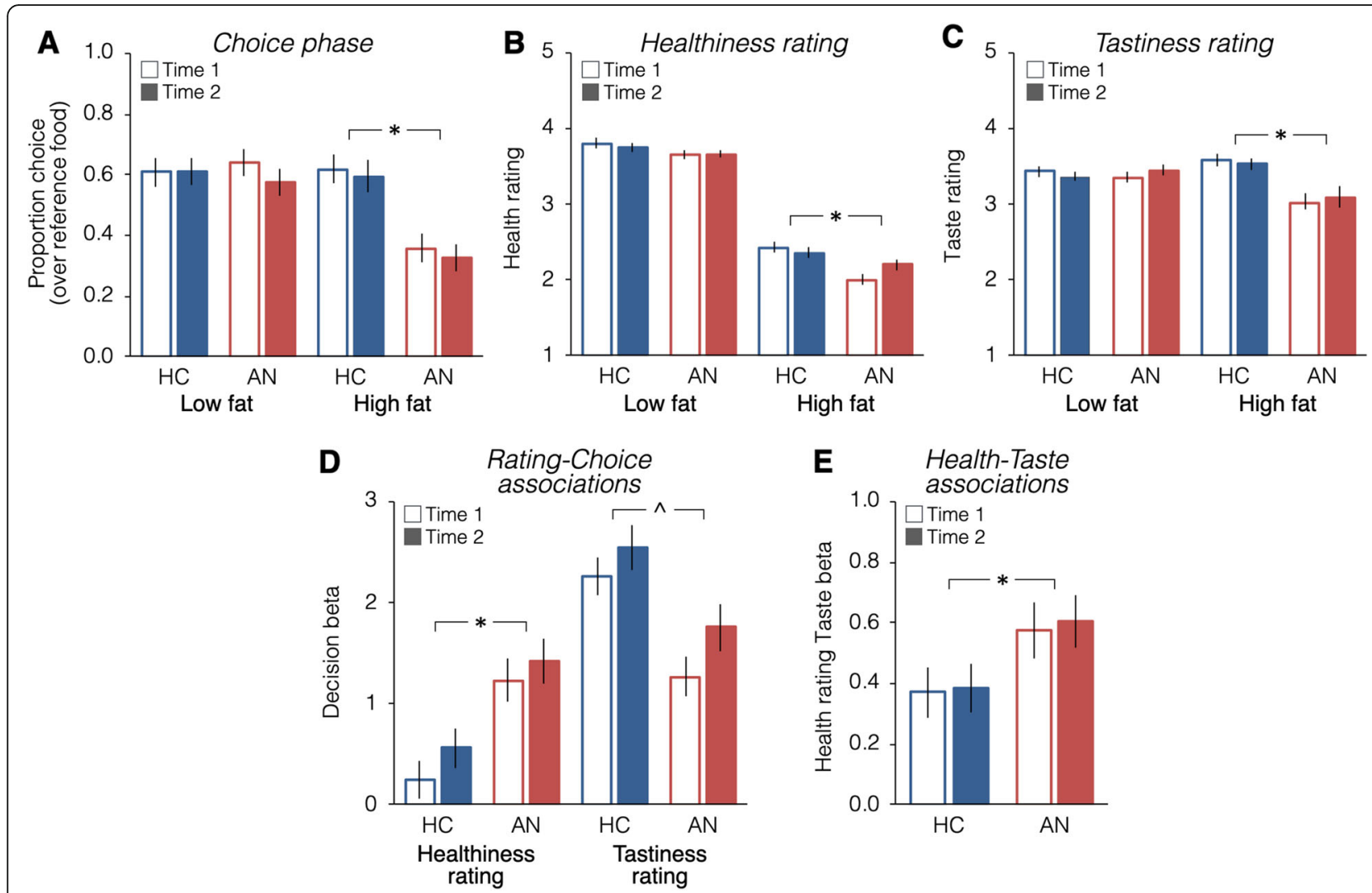

Fig. 2 Food choice task behavior at Time 1 and Time 2. a High-fat and low-fat food choices did not change significantly from Time 1 to Time 2 (ps > 0.37). The AN group made fewer high-fat, but not low-fat, food choices before and after treatment (Supplemental Table S2). b Overall low-fat items were rated higher on healthiness than high-fat items. High-fat foods were rated as lower in healthiness than low-fat foods overall and the groups differed significantly (Supplemental Table S3). c The AN group rated high-fat foods specifically lower in tastiness than did the HC group and this did not change with treatment (Supplemental Table S4). $\mathbf{d}$ Logistic regression of Healthiness and Tastiness ratings on choice. Choice was influenced more by tastiness among HC than AN, whereas choice was influenced more by healthiness among AN relative to HC (Supplemental Table S5). e Regression of Healthiness on Tastiness ratings. Ratings were more strongly associated among AN than HC (Supplemental Table S6). * indicates $p<0.05 . \wedge$ indicates significant Group difference and significant difference between Time 1 and Time 2 in both groups

$p=0.037$, robust regression: $p=0.036$; Fig. $3 \mathrm{a}$ ). This relationship between neural activation and behavior was not found among the $\mathrm{HC}\left(\mathrm{r}_{27}=-0.11, p=0.57\right.$; Fig. 3a). Changes in choices of low-fat foods were not related to caudate engagement in either group (AN: $r_{22}=-0.08$, $\left.p=0.70 ; \mathrm{HC}: \mathrm{r}_{27}=-0.02, p=0.90\right)$.

\section{Prefrontal cortex activity and food choice}

As in previous studies [12, 19], there was significant choice-related activation in the VMPFC ROI. That activation did not differ between groups $(F[1,51]=0.007$, $p=0.93)$ or across time $(\mathrm{F}[1,51]=0.57, p=0.45)$ nor was there a significant interaction $(\mathrm{F}[1,51]=0.19, p=0.67$; Fig. 3b). We additionally explored whether the DLPFC, previously implicated in the use of self-control for food choices [12], was differentially engaged across groups and time, but found no significant differences (Time: $\mathrm{F}$ $[1,51]=0.16, p=0.69$; Group: $\mathrm{F}[1,51]=1.32, p=0.26$; Group x Time: F $[1,51]=1.00, p=0.32$; Fig. 3c). There were no effects of Group or Time during Healthiness and Tastiness ratings ( $p s>0.05$; Supplemental Figure S1BC).

Whole-brain analyses to explore areas outside a priori ROIs revealed a group difference at Time 1 in the superior parietal lobule/precuneus, with greater choice related engagement in the AN than the HC group (Supplemental Figure 2). To examine changes over time in the parietal region, we extracted values at Time 2 from the cluster identified at Time 1 . There were no group differences at Time $2\left(t_{51}=-0.15, p=0.88\right.$; Group $\mathrm{X}$ Time Interaction: $\mathrm{F}[1,51]=6.67, p=0.013$; Fig. $3 \mathrm{~d}$ ). For completeness, as for the anterior caudate, we explored the relationship between changes from Time 1 to Time 2 in the parietal region and high-fat food choice changes and found a significant correlation $\left(\mathrm{r}_{22}=-0.476, p=0.019\right.$; robust regression: $p=0.022$; Fig. $3 \mathrm{~d}$ ). Changes over time in the anterior caudate and parietal lobe were significantly correlated in the AN group $(\mathrm{r}=0.745, p<0.001)$ 

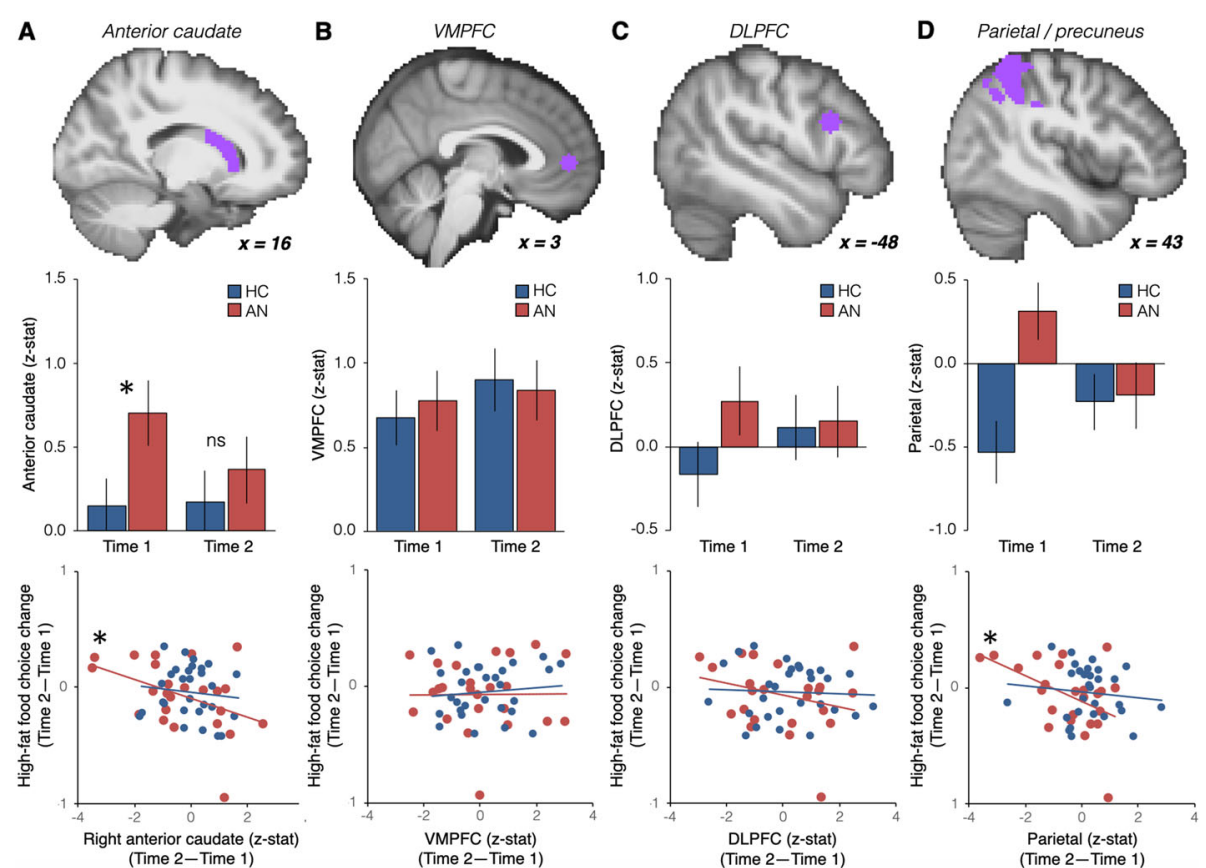

Fig. 3 Choice-related engagement in regions of interest before and after treatment and relationship with eating behavior. a Values extracted from the parametric choice analysis in our a priori anatomical ROI in the right anterior caudate (top panel). Choice-related activation in the caudate differed significantly between $\mathrm{HC}$ and AN at Time 1, but not at Time 2 (middle panel). Change in activity in the caudate from Time 1 to Time 2 was significantly correlated with the change in proportion high-fat food choices on the food choice task among individuals with AN, but not HC. Robust regression was used due to the presence of outliers. b Same analyses as in a for the a priori VMPFC ROI (MNI = [3 513 3]; top panel). c Same analyses as in a for the a priori DLPFC ROI (MNI = [- 4815 24]; top panel). d For illustration purposes the same analyses as in a are presented for the parietal region identified in exploratory whole-brain analyses

but not in the HC group ( $\mathrm{r}=0.338, p=0.073)$; the difference in correlation between groups was significant $(p=$ 0.038).

Whole-brain analyses of the Choice phase (Supplemental Figure S2), Healthiness rating phase (Supplemental Figure S3), and Tastiness rating phase (Supplemental Figure S4) did not reveal any other regions that changed between Time 1 and Time 2 or differed between groups.

\section{Discussion}

This study tested whether neural mechanisms associated with maladaptive food choice in AN change with acute weight restoration. The fMRI findings during a Food Choice Task immediately following hospital admission were consistent with prior results, with greater choicerelated engagement of the anterior caudate among individuals with $\mathrm{AN}$. Increased selection of high-fat foods following weight restoration was associated with decreased choice-related caudate activation. On average, however, patients with AN did not substantially increase their selection of high-fat foods from Time 1 to Time 2, consistent with a prior study demonstrating the persistence of dietary restriction after treatment [9]. Additionally, whole brain analyses identified choice-related activation in a parietal/precuneus region that normalized with weight restoration. Change over time in this region was also associated with food-choice change and with caudate change. These findings underscore the association between restrictive eating and choice-related activation of the caudate in AN and suggest this brain-behavior link may be a target for treatment development.

The lack of change in choice of high-fat foods for a snack after $\sim 2.5$ months of hospital care is disappointing, though not surprising. The challenge of changing eating behavior, even during inpatient treatment, has been demonstrated in laboratory meal studies $[8,9]$ and is consistent with the high rate of relapse following hospital discharge. The ability to select a diet higher in energy density at the end of hospital care is associated with better treatment outcomes 1 year later $[4,50]$, suggesting that interventions that effect change in dietary patterns are likely necessary to decrease relapse. The caudate region implicated here is important for action control and choice, in general [51]. Change in maladaptive behavior in AN may depend on therapeutic techniques that focus directly on the difficult problem of changing food choices. A habit reversal based approach that targeted cues for maladaptive eating routines was successful in changing behavior in AN in a pilot study [52]. Similarly, exposure therapies that emphasize finer-grained focus on maladaptive eating have 
also shown promise [53]. Neuromodulation of the dorsal frontostriatal system using transcranial magnetic stimulation (TMS) showed some impact in decreasing excessive self-control over food choices among individuals with chronic AN [20]. Targeting the brain systems identified here may amplify the effects of existing treatments for AN.

In addition to the a priori ROI analyses that largely confirmed hypotheses about the caudate in food-based decision making in AN, exploratory whole-brain analyses suggested that the brain-behavior link also includes parietal/precuneus regions. The parietal lobe has been implicated in decision making and choice [54, 55]. In addition, parietal cortex is often considered part of a cognitive control network (fronto-cingulo-parietal system) [56-58], with functions that could be relevant for food choice (e.g., selective attention, response inhibition, etc.). The precuneus has been shown to play a role in a variety of higher cognitive functions, including selfreferential processing and episodic memory retrieval [59]. Abnormalities in precuneus activation among individuals with AN have been identified several studies that include food related tasks [60-62] and, notably, is the most highly implicated region associated with the term 'anorexia nervosa' on the Neuroquery meta-analysis tool [63]. While the present study design does not allow for inferences about the specific contribution to decisionmaking, the findings suggest that further investigation of these cognitive processes is warranted. Although, reverse inference of cognitive processes based on brain activity is of limited utility, one hypothesis potentially worth investigating based on differential engagement of the precuneus among $\mathrm{AN}$ and $\mathrm{HC}$, is that individuals with $\mathrm{AN}$ rely on memory retrieval differently than do $\mathrm{HC}$; the role of episodic memories in decision making among individuals with AN has not been carefully examined. These cortical regions might also be targets for neuromodulation.

There are limited data about brain systems that contribute to the persistence of AN, especially as few studies have examined neural systems before and after treatment. The mean age and duration of illness in this study is representative of a general sample of treatment seeking adults, and is within the range seen in across neuroimaging research [64]. However, duration of illness has not been systematically considered in neuroimaging studies in AN, and may influence brain findings [65]. Existing longitudinal data, across different imaging modalities, have indicated that renourishment is associated with some brain changes. For example, structural brain abnormalities, such as gray matter volume decreases and cortical thinning, are seen among individuals with $\mathrm{AN}$ at low weight and tend to normalize with weight restoration [66-68]. However, studies of white matter abnormalities have not consistently reported normalization with weight restoration [69, 70]. One task-based fMRI study indicated that learning related response abnormalities in the striatum normalized after weight restoration [71]. Two studies of monetary decision-making found increases in neural activity in the striatum [72] and the dorsal anterior cingulate after weight restoration [73]. These studies together indicate that the brain is altered by starvation (and by renourishment) and that fronto-striatal circuits are among regions that undergo change across multiple studies and modalities. The stability of the neural response in the $\mathrm{HC}$ group in the present study supports the utility of the longitudinal assessments and strengthens the ability to draw inferences from the changes seen in the AN group. And, unlike prior longitudinal research, the present study directly examined treatment-associated changes in neural mechanisms of restrictive eating - the behavioral disturbance most directly connected to relapse, morbidity, and mortality. These findings highlight the value of explicitly linking brain and behavior by using a task demonstrated to capture maladaptive eating behavior in AN.

\section{Limitations}

The current results should be viewed in light of several limitations. First, the sample size was modest, and it is possible that there was insufficient power to detect the full effect of treatment on neural circuits. Small sample size is a common limitation in studies of AN and suggests a need for standardization of methods such that studies can be pooled. Second, patients were studied at the end of acute inpatient treatment, shortly after full weight restoration. While weight restoration is a necessary first step in treatment of AN, it is not associated with full resolution of psychological and behavioral symptoms and may not be the optimal moment to assess brain changes in AN. On the other hand, it has been suggested that neural changes should precede behavioral effects, hopefully permitting understanding of the neural mechanisms of treatment response [74]. Third, examination of brain regions that may become engaged only after weight restoration was limited by a priori regional hypotheses. It may be that the ROIs selected (VMPFC and DLPFC) were not the most relevant or sensitive to change and, in this small study, we were unable to detect other regions of increased activation in a whole brain analysis.

\section{Conclusions}

By linking brain and behavior, this study confirmed previous findings that during active decisions about what to eat, acutely ill individuals with AN differed from $\mathrm{HC}$ in engagement of the anterior caudate. The change 
(decrease) in caudate activation after treatment was associated with an increased tendency to choose high-fat foods, and similar activation patterns occurred in the parietal/precuneus region. Additional research is needed to determine whether food choice behavior-and associated neural mechanisms-change with longer-term remission.

\begin{abstract}
Abbreviations
AN: Anorexia nervosa; BMI: Body mass index; BOLD: Blood-oxygen level dependent; DLPFC: Dorsolateral prefrontal cortex; GLM: General linear model; HC: Healthy control volunteer; ITI: Intertrial interval; NYSPI: New York State Psychiatric Institute; VMPFC: Ventromedial prefrontal cortex; IQ: Intelligence quotient; DICOM: Digital Imaging and Communications in Medicine; NIFTI: Neuroimaging Informatics Technology Initiative; FSL: FMRIB Software Library; MNI: Montreal Neurological Institute; FD: Framewise Displacement
\end{abstract}

\section{Supplementary Information}

The online version contains supplementary material available at https://doi. org/10.1186/s40337-021-00402-y.

\section{Additional file 1.}

\section{Acknowledgments}

We would like to thank Akram Bakkour, PhD for technical assistance with the data analyses, and thoughtful contributions to discussions of these data. The authors would like to thank the patients and staff of the New York State Psychiatric Institute for their contributions to this research.

\section{Authors' contributions}

JS, DS, KF, and BTW conceptualized and designed the study. KF conducted analyses and DS and ND contributed to analytic design and interpretation. MD contributed to data collection and management, and manuscript review. JS, KF, and BTW wrote and edited the manuscript. All authors reviewed the manuscript. The author(s) read and approved the final manuscript.

\section{Funding}

This work was supported by National Institute of Mental Health R01 MH105452; R01 MH105452 S1; K24 MH113737.

\section{Availability of data and materials}

The datasets analyzed during the current study are available from the corresponding author on reasonable request. The food choice task stimuli and nutritional content are publicly available at Columbia Academic Commons (https://doi.org/10.7916/d8-497c-2724) and Open Science Framework (https:// osf.io/483mx/); information included in Lloyd et al., 2020 [17]

\section{Declarations}

\section{Ethics approval and consent to participate}

This study was approved by the New York State Psychiatric Institute Institutional Review Board (Protocol \#6717) and all participants signed informed consent.

\section{Consent for publication}

Not applicable.

\section{Competing interests}

Dr. Steinglass receives royalties from UpToDate. Dr. Walsh reports receiving royalties and honoraria from Guilford Press, McGraw-Hill, Oxford University Press, UpToDate, British Medical Journal, Johns Hopkins Press and Guidepoint Global. Drs. Daw, Foerde, and Shohamy and Ms. Dalack report no financial relationships with commercial interests.

\section{Author details}

1 New York State Psychiatric Institute, 1051 Riverside Drive, Unit 98, New York NY 10032, USA. ${ }^{2}$ Psychiatry Department, Columbia University Irving Medical
Center, 1051 Riverside Drive, Unit 98, New York, NY 10032, USA. ${ }^{3}$ Princeton Neuroscience Institute, Department of Psychology, Princeton University, Princeton, NJ 08540, USA. ${ }^{4}$ Psychology Department and Zuckerman Mind Brain and Behavior Institute, Columbia University, 3227 Broadway, New York, NY 10027, USA.

Received: 26 January 2021 Accepted: 31 March 2021

Published online: 17 April 2021

\section{References}

1. American Psychiatric Association. Treatment of patients with eating disorders,third edition. Am J Psychiatry. 2006;163(7 Suppl):4-54.

2. Attia E, Walsh BT. Behavioral management for anorexia nervosa. N Engl J Med. 2009;360(5):500-6. https://doi.org/10.1056/NEJMct0805569.

3. Khalsa SS, Portnoff LC, McCurdy-McKinnon D, Feusner JD. What happens after treatment? A systematic review of relapse, remission, and recovery in anorexia nervosa. J Eat Disord. 2017;5(1):20. https://doi.org/10.1186/s40337017-0145-3.

4. Schebendach J, Mayer LE, Devlin MJ, Attia E, Walsh BT. Dietary energy density and diet variety as risk factors for relapse in anorexia nervosa: a replication. Int J Eat Disord. 2012;45(1):79-84. https://doi.org/10.1002/eat.2 0922

5. Attia E, Haiman C, Walsh BT, Flater SR. Does fluoxetine augment the inpatient treatment of anorexia nervosa? Am J Psychiatry. 1998;155(4):54851. https://doi.org/10.1176/ajp.155.4.548.

6. Kaplan AS, Walsh BT, Olmsted M, Attia E, Carter JC, Devlin MJ, et al. The slippery slope: prediction of successful weight maintenance in anorexia nervosa. Psychol Med. 2009;39(6):1037-45. https://doi.org/10.1017/S0033291 $70800442 X$

7. Uniacke B, Wang Y, Biezonski D, Sussman T, Lee S, Posner J, et al. Restingstate connectivity within and across neural circuits in anorexia nervosa. Brain Behav. 2019;9(1):e01205. https://doi.org/10.1002/brb3.1205.

8. Sysko R, Walsh BT, Schebendach J, Wilson GT. Eating behavior among women with anorexia nervosa. Am J Clin Nutr. 2005;82(2):296-301. https://doi.org/10.1093/ajcn/82.2.296.

9. Mayer LE, Schebendach J, Bodell LP, Shingleton RM, Walsh BT. Eating behavior in anorexia nervosa: before and after treatment. Int J Eat Disord. 2012;45(2):290-3. https://doi.org/10.1002/eat.20924.

10. Rangel A, Camerer C, Montague PR. A framework for studying the neurobiology of value-based decision making. Nat Rev Neurosci. 2008;9(7): 545-56. https://doi.org/10.1038/nrn2357.

11. Rangel A. Regulation of dietary choice by the decision-making circuitry. Nat Neurosci. 2013;16(12):1717-24. https://doi.org/10.1038/nn.3561.

12. Hare TA, Camerer CF, Rangel A. Self-control in decision-making involves modulation of the vmPFC valuation system. Science. 2009;324(5927):646-8. https://doi.org/10.1126/science.1168450.

13. Hare TA, Malmaud J, Rangel A. Focusing attention on the health aspects of foods changes value signals in vmPFC and improves dietary choice. J Neurosci. 2011;31(30):11077-87. https://doi.org/10.1523/JNEUROSCI.6383-1 0.2011

14. Krajbich I, Armel C, Rangel A. Visual fixations and the computation and comparison of value in simple choice. Nat Neurosci. 2010;13(10):1292-8. https://doi.org/10.1038/nn.2635.

15. Maier SU, Raja Beharelle A, Polania R, Ruff CC, Hare TA. Dissociable mechanisms govern when and how strongly reward attributes affect decisions. Nat Hum Behav. 2020:4(9):949-63. https://doi.org/10.1038/s41562-020-0893-y.

16. Suzuki S, Cross L, O'Doherty JP. Elucidating the underlying components of food valuation in the human orbitofrontal cortex. Nat Neurosci. 2017:20(12): 1780-6. https://doi.org/10.1038/s41593-017-0008-x.

17. Lloyd EC, Shehzad Z, Schebendach J, Bakkour A, Xue AM, Assaf NF, et al. Food Folio by Columbia Center for Eating Disorders: A Freely Available Food Image Database. Front Psychol. 2020;11(3556). https://doi.org/10.3389/ fpsyg.2020.585044

18. Foerde K, Schebendach JE, Davis L, Daw N, Walsh BT, Shohamy D, et al. Restrictive eating across a spectrum from healthy to unhealthy: behavioral and neural mechanisms. Psychol Med. 2020:1-10. https://doi.org/10.1017/ S0033291720003542

19. Foerde K, Steinglass JE, Shohamy D, Walsh BT. Neural mechanisms supporting maladaptive food choices in anorexia nervosa. Nat Neurosci. 2015;18(11):1571-3. https://doi.org/10.1038/nn.4136. 
20. Dalton B, Foerde K, Bartholdy S, McClelland J, Kekic M, Grycuk L, et al. The effect of repetitive transcranial magnetic stimulation on food choice-related self-control in patients with severe, enduring anorexia nervosa. Int J Eat Disord. 2020;53(8):1326-36. https://doi.org/10.1002/eat.23267.

21. Steinglass J, Foerde K, Kostro K, Shohamy D, Walsh BT. Restrictive food intake as a choice--a paradigm for study. Int J Eat Disord. 2015;48(1):59-66. https://doi.org/10.1002/eat.22345.

22. Uniacke B, Slattery R, Walsh BT, Shohamy D, Foerde K, Steinglass JE. A comparison of food-based decision making between restricting and bingeeating/purging subtypes of anorexia nervosa. In J Eat Disord. 2020;53(10): 1751-6. https://doi.org/10.1002/eat23359.

23. Foerde K, Gianini L, Wang Y, Wu P, Shohamy D, Walsh BT, et al. Assessment of test-retest reliability of a food choice task among healthy individuals. Appetite. 2018;123:352-6. https://doi.org/10.1016/j.appet.2018.01.010.

24. Bartra O, McGuire JT, Kable JW. The valuation system: a coordinate-based meta-analysis of BOLD fMRI experiments examining neural correlates of subjective value. Neuroimage. 2013;76:412-27. https://doi.org/10.1016/j. neuroimage.2013.02.063.

25. American Psychiatric Association. Diagnostic and statistical manual of mental disorders. 5th ed. Arlington: American Psychiatric Association; 2013. https://doi.org/10.1176/appi.books.9780890425596.

26. Sysko R, Glasofer DR, Hildebrandt T, Klimek P, Mitchell JE, Berg KC, et al. The eating disorder assessment for DSM-5 (EDA-5): development and validation of a structured interview for feeding and eating disorders. Int J Eat Disord. 2015;48(5):452-63. https://doi.org/10.1002/eat.22388.

27. Brainard DH. The psychophysics toolbox. Spat Vis. 1997;10(4):433-6. https:// doi.org/10.1163/156856897X00357.

28. JASP Team (2020). JASP (Version 0.14.1)[Computer software].

29. Bates D, Maechler M, Bolker B, Walker S. Ime4: linear mixed-effects models using Eigen and S4. R package version. 2014;1(7):1-23.

30. Barr DJ, Levy R, Scheepers C, Tily HJ. Random effects structure for confirmatory hypothesis testing: Keep it maximal. J Mem Lang. 2013;68(3): 255-78. https://doi.org/10.1016/j.jml.2012.11.001.

31. Barr DJ. Random effects structure for testing interactions in linear mixed-effects models. Front Psychol. 2013;4:328. https://doi.org/10.3389/fpsyg.2013.00328.

32. Venables WN, Ripley BD. Modern applied statistics with S. Fourth ed. New York: Springer; 2002. https://doi.org/10.1007/978-0-387-21706-2.

33. Smith SM, Jenkinson M, Woolrich MW, Beckmann CF, Behrens TE, JohansenBerg $\mathrm{H}$, et al. Advances in functional and structural MR image analysis and implementation as FSL. Neuroimage. 2004;23(Suppl 1):S208-19. https://doi. org/10.1016/j.neuroimage.2004.07.051.

34. Jenkinson M, Bannister P, Brady M, Smith S. Improved optimization for the robust and accurate linear registration and motion correction of brain images. Neuroimage. 2002:17(2):825-41. https://doi.org/10.1006/nimg.2002.1132.

35. Smith SM. Fast robust automated brain extraction. Hum Brain Mapp. 2002; 17(3):143-55. https://doi.org/10.1002/hbm.10062.

36. Fischl B, Sereno MI, Tootell RB, Dale AM. High-resolution intersubject averaging and a coordinate system for the cortical surface. Hum Brain Mapp. 1999;8(4):272-84. https://doi.org/10.1002/(SICI)1097-0193(1999)8:4< 272::AID-HBM10>3.0.CO;2-4

37. Segonne F, Dale AM, Busa E, Glessner M, Salat D, Hahn HK, et al. A hybrid approach to the skull stripping problem in MRI. Neuroimage. 2004;22(3): 1060-75. https://doi.org/10.1016/j.neuroimage.2004.03.032.

38. Andersson $J$, Jenkinson $M$, Smith S. Non-linear registration aka spatial normalisation FMRIB Technial report TR07JA2. Oxford: FMRIB Analysis Group of the University of Oxford; 2007

39. Power JD, Barnes KA, Snyder AZ, Schlaggar BL, Petersen SE. Spurious but systematic correlations in functional connectivity MRI networks arise from subject motion. Neuroimage. 2012;59(3):2142-54. https://doi.org/10.1016/j. neuroimage.2011.10.018

40. Siegel JS, Power JD, Dubis JW, Vogel AC, Church JA, Schlaggar BL, et al. Statistical improvements in functional magnetic resonance imaging analyses produced by censoring high-motion data points. Hum Brain Mapp. 2014:35(5):1981-96. https://doi.org/10.1002/hbm.22307.

41. Bodell LP, Keel PK, Brumm MC, Akubuiro A, Caballero J, Tranel D, et al. Longitudinal examination of decision-making performance in anorexia nervosa: before and after weight restoration. J Psychiatr Res. 2014;56:150-7. https://doi.org/10.1016/j.jpsychires.2014.05.015.

42. Eklund A, Nichols TE, Knutsson H. Cluster failure: why fMRI inferences for spatial extent have inflated false-positive rates. Proc Natl Acad Sci U S A. 2016;113(28):7900-5. https://doi.org/10.1073/pnas.1602413113.
43. Bakkour A, Palombo DJ, Zylberberg A, Kang YH, Reid A, Verfaellie M Shadlen MN, Shohamy D. The hippocampus supports deliberation during value-based decisions. Elife. 2019;8:e46080. https://doi.org/10.7554/eLife.4 6080.

44. Beck AT, Steer RA. Depression inventory manual. San Antonio: Psychological Corporation, Harcourt, Brace; 1993.

45. Fairburn CG, Beglin SJ. Assessment of eating disorders: interview or selfreport questionnaire? Int J Eat Disord. 1994;16(4):363-70.

46. Wechsler D. Wechsler Adult Intelligence Scale - III. San Antonio: The Psychological Corporation; 1997.

47. Spielberger CD, Gorsuch RL, Lushene R, Vagg PR, Jacobs AG. Manual for the state-trait anxiety inventory. Palo Alto: Consulting Psychologists Press, Inc.; 1983.

48. Stunkard AJ, Messick S. The three-factor eating questionnaire to measure dietary restraint, disinhibition and hunger. J Psychosom Res. 1985;29(1):7183. https://doi.org/10.1016/0022-3999(85)90010-8.

49. Wechsler D. Wechsler abbreviated scale of intelligence manual. San Antonio: The Psychological Corporation; 1999

50. Schebendach JE, Mayer LE, Devlin MJ, Attia E, Contento IR, Wolf RL, et al. Dietary energy density and diet variety as predictors of outcome in anorexia nervosa. Am J Clin Nutr. 2008;87(4):810-6. https://doi.org/1 0.1093/ajcn/87.4.810.

51. Liljeholm M, O'Doherty JP. Contributions of the striatum to learning motivation, and performance: an associative account. Trends Cogn Sci. 2012;16(9):467-75. https://doi.org/10.1016/j.tics.2012.07.007.

52. Steinglass JE, Glasofer DR, Walsh E, Guzman G, Peterson CB, Walsh BT, et al. Targeting habits in anorexia nervosa: a proof-of-concept randomized trial. Psychol Med. 2018;48(15):2584-91. https://doi.org/10.1017/S00332917180002 OX.

53. Butler RM, Heimberg RG. Exposure therapy for eating disorders: a systematic review. Clin Psychol Rev. 2020;78:101851. https://doi.org/10.1016/j.cpr.2020.1 01851.

54. Platt ML, Glimcher PW. Neural correlates of decision variables in parietal cortex. Nature. 1999:400(6741):233-8. https://doi.org/10.1038/22268.

55. Pesaran B, Nelson MJ, Andersen RA. Free choice activates a decision circuit between frontal and parietal cortex. Nature. 2008;453(7193):406-9. https:// doi.org/10.1038/nature06849.

56. Niendam TA, Laird AR, Ray KL, Dean YM, Glahn DC, Carter CS. Meta-analytic evidence for a superordinate cognitive control network subserving diverse executive functions. Cogn Affect Behav Neurosci. 2012;12(2):241-68. https:// doi.org/10.3758/s13415-011-0083-5.

57. Derrfuss J, Brass M, Neumann J, von Cramon DY. Involvement of the inferior frontal junction in cognitive control: meta-analyses of switching and Stroop studies. Hum Brain Mapp. 2005;25(1):22-34. https://doi.org/10.1002/hbm.2 0127.

58. Rae CL, Hughes LE, Weaver C, Anderson MC, Rowe JB. Selection and stopping in voluntary action: a meta-analysis and combined fMRI study. Neuroimage. 2014;86:381-91. https://doi.org/10.1016/j.neuroimage.2013.10. 012.

59. Cavanna AE, Trimble MR. The precuneus: a review of its functional anatomy and behavioural correlates. Brain. 2006;129(Pt 3):564-83. https://doi.org/10.1 093/brain/awl004.

60. Jiang T, Soussignan R, Carrier E, Royet JP. Dysfunction of the mesolimbic circuit to food odors in women with anorexia and bulimia nervosa: a fMRI study. Front Hum Neurosci. 2019;13:117. https://doi.org/10.3389/fnhum.2019. 00117.

61. Brooks SJ, O'Daly OG, Uher R, Friederich HC, Giampietro V, Brammer M, et al Differential neural responses to food images in women with bulimia versus anorexia nervosa. Plos One. 2011;6(7):e22259. https://doi.org/10.1371/journal. pone.0022259.

62. Nikendei C, Friederich HC, Weisbrod M, Walther S, Sharma A, Herzog W, et al. Event-related potentials during recognition of semantic and pictorial food stimuli in patients with anorexia nervosa and healthy controls with varying internal states of hunger. Psychosom Med. 2012;74(2):136-45. https://doi.org/10.1097/PSY.0b013e318242496a.

63. Dockes J, Poldrack RA, Primet R, Gozukan H, Yarkoni T, Suchanek F, et al. NeuroQuery, comprehensive meta-analysis of human brain mapping. Elife. 2020;9. https://doi.org/10.7554/eLife.53385.

64. Alfano V, Mele G, Cotugno A, Longarzo M. Multimodal neuroimaging in anorexia nervosa. J Neurosci Res. 2020;98(11):2178-207. https://doi.org/10.1 002/jnr.24674 
65. Steinglass J, Glasofer D, Dalack M, Attia E. Between wellness, relapse and remission: Stages of illness in anorexia nervosa. Int J Eat Disord. 2020; 53(7): 1088-96. https://doi.org/10.1002/eat.23237.

66. Nickel K, Joos A, Tebartz van Elst L, Matthis J, Holovics L, Endres D, et al. Recovery of cortical volume and thickness after remission from acute anorexia nervosa. Int J Eat Disord. 2018;51(9):1056-69. https://doi.org/10.1 002/eat.22918

67. von Schwanenflug N, Muller DK, King JA, Ritschel F, Bernardoni F, Mohammadi $\mathrm{S}$, et al. Dynamic changes in white matter microstructure in anorexia nervosa: findings from a longitudinal study. Psychol Med. 2019; 49(9):1555-64. https://doi.org/10.1017/S003329171800212X.

68. Bernardoni F, King JA, Geisler D, Stein E, Jaite C, Natsch D, et al. Weight restoration therapy rapidly reverses cortical thinning in anorexia nervosa: a longitudinal study. Neuroimage. 2016;130:214-22. https://doi.org/10.1016/j. neuroimage.2016.02.003

69. Martin Monzon B, Hay P, Foroughi N, Touyz S. White matter alterations in anorexia nervosa: a systematic review of diffusion tensor imaging studies. World J Psychiatry. 2016;6(1):177-86. https://doi.org/10.5498/wjp.v6.i1.177.

70. Cha J, Ide JS, Bowman FD, Simpson HB, Posner J, Steinglass JE. Abnormal reward circuitry in anorexia nervosa: a longitudinal, multimodal MRI study. Hum Brain Mapp. 2016;37(11):3835-46. https://doi.org/10.1002/hbm.23279.

71. DeGuzman M, Shott ME, Yang TT, Riederer J, Frank GKW. Association of elevated reward prediction error response with weight gain in adolescent anorexia nervosa. Am J Psychiatry. 2017;174(6):557-65. https://doi.org/10.11 76/appi.ajp.2016.16060671.

72. Decker JH, Figner B, Steinglass JE. On weight and waiting: delay discounting in anorexia nervosa pretreatment and posttreatment. Biol Psychiatry. 2015; 78(9):606-14. https://doi.org/10.1016/j.biopsych.2014.12.016.

73. Doose A, King JA, Bernardoni F, Geisler D, Hellerhoff I, Weinert T, et al. Strengthened Default Mode Network Activation During Delay Discounting in Adolescents with Anorexia Nervosa After Partial Weight Restoration: A Longitudinal fMRI Study. J Clin Med. 2020;9(4). https://doi.org/10.3390/ jcm9040900. Epub date 2020/03/29.

74. Chung T, Noronha A, Carroll KM, Potenza MN, Hutchison K, Calhoun VD, et al. Brain mechanisms of change in addictions treatment: models, methods, and emerging findings. Curr Addict Rep. 2016;3(3):332-42. https:// doi.org/10.1007/s40429-016-0113-z.

\section{Publisher's Note}

Springer Nature remains neutral with regard to jurisdictional claims in published maps and institutional affiliations.

Ready to submit your research? Choose BMC and benefit from:

- fast, convenient online submission

- thorough peer review by experienced researchers in your field

- rapid publication on acceptance

- support for research data, including large and complex data types

- gold Open Access which fosters wider collaboration and increased citations

- maximum visibility for your research: over $100 \mathrm{M}$ website views per year

At $\mathrm{BMC}$, research is always in progress.

Learn more biomedcentral.com/submissions 